\title{
Vorankündigung ÖGUM-Highlights in 2014
}

\author{
Wir wollen für Ihre frühzeitige Planung schon auf 2 Veranstal- \\ tungen hinweisen, die im kommenden Jahr von der ÖGUM aus- \\ gerichtet und organisiert werden:
}

\author{
EUROSON School - CEUS Course, \\ 21.-22. Februar 2014, Wien \\ $\nabla$
}

Die österreichische Gesellschaft für Ultraschallmedizin (ÖGUM) freut sich einen weiteren EUROSONSCHOOL-CEUS Course in Wien von 21.- 22. Februar 2014 zu veranstalten.

Dieser Kurs gibt den TeilnehmerInnen die Möglichkeit Grundkenntnisse in der Durchführung von kontrastmittelverstärktem Ultraschall zu erlangen, die neuesten CEUS-Rahmenbedingungen aus erster Hand zu erfahren und an aktuellen Fallbeispielen zu lernen.

Nähere Details zum aktuellen Programm und der Online-Anmeldung finden Sie auf der Homepage www.oegum.at.

Kurssprache

Englisch

Ultraschall 2014 -

38. Dreiländertreffen der ÖGUM / DEGUM / SGUM, 29.-31. Oktober 2014, Innsbruck

$\nabla$

Unsere Präsidentin-Elect Univ. Doz. Dr. Andrea Klauser und ihr Team haben schon mit viel Engagement Vorarbeiten geleistet, damit auch das kommende Dreiländertreffen auf heimischen Boden wieder mit einem großen Lehr- und Informationsangebot starten kann. Die aktuellen

\section{Veranstaltungsort}

Veranstaltungszentrum Europahaus

Wien, Linzer Straße 429, AT-1140 Vienna

\section{Kursorganisatoren}

C. Aiginger, Vienna/AT, G. Mathis, Rankweil/AT, H. Prosch, Vienna/AT

\section{Anmeldung und Informationen}

ÖGUM Geschäftsstelle

Beate Kasperak, Katharina Kortschak;

Neutorgasse 9, AT-1010 Wien

Tel.: ++435351305

E-Mail: Katharina.Kortschak@myesr.org
Informationen erhalten Sie unter www. ultraschall2014.at oder via abgebildetem QR-code

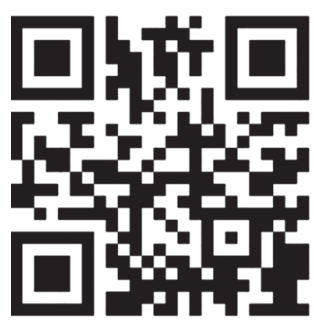

